
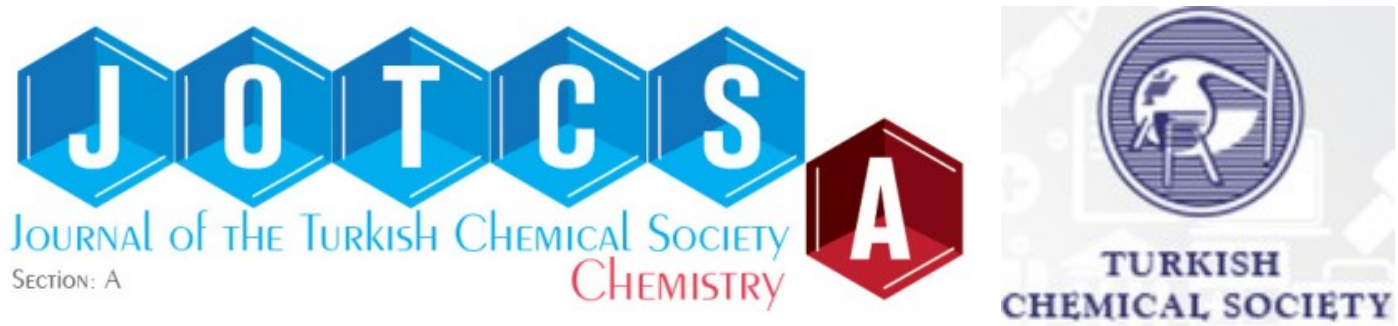

\title{
Evaluation of phytochemical contents and antioxidant activity of pomegranate flower
}

\author{
Zehra Tekin $\triangle(D)$ F. Zehra Küçükbay* $M$ \\ İnönü University, Faculty of Pharmacy, Department of Basic Pharmaceutical Sciences, \\ Malatya, Turkey
}

\begin{abstract}
Pomegranate is one of the most abundant fruits consumed in Turkey. This study aimed to determine the content of total phenolic, total flavonoid, and antioxidant activity of Punica granatum L. flower in different extracts. Antioxidant activities of different extracts were determined 2,2-diphenyl-1picrylhydrazyl (DPPH•) radical scavenging, reducing power, and metal chelating methods. The results showed that the total phenolic content for the extracts ranged from 14.82 to 90.86 mg gallic acid equivalents (GAE) / $\mathrm{g}$ extract. The contents of flavonoids were found to range from 7.35 to $500.00 \mathrm{mg}$ quercetin equivalents (QUE)/g extract. All pomegranate flower extracts displayed remarkable antioxidant activity according to DPPH and reducing power assays. Especially the methanolic extract of pomegranate flower possesses significant scavenging activity against DPPH $\bullet(85.80 \%)$, as well as the largest contents of flavonoids and phenolic compounds. The antioxidant capacity of the methanolic extract was also greater than those of BHT and a-tocopherol in DPPH and reducing power assays. The results demonstrated that the antioxidant activity of extracts of Punica granatum L. flower might, at least in part, have high content of flavonoids and other phenolics.
\end{abstract}

Keywords: Pomegranate flower, Punica granatum Linn., antioxidant activity, phenolic compounds.

Submitted: July 31, 2019. Accepted: October 11, 2019.

Cite this: Tekin Z, Küçükbay F. Evaluation of phytochemical contents and antioxidant activity of pomegranate flower. JOTCSA. 2020;7(1):37-42.

DOI: https://doi.org/10.18596/jotcsa.628615.

*Corresponding author. E-mail: zehra.kucukbay@inonu.edu.tr.

\section{INTRODUCTION}

Punica granatum Linn. known as pomegranate is a member of the Punicaceae family. Pomegranate is a famous ancient fruit originating from the Middle East. Main producers and exporters in the world are Turkey, India, Iran, China, United States, Spain, South Africa, Peru, Chile, and Argentina (1). In Turkey, the annual production of pomegranate is 537.847 tons and it is cultivated in Adıyaman, Mersin, Antalya, Adana, Gaziantep, and Şanlıurfa (2).
Pomegranate possesses a broad array of pharmacological properties such as antioxidant (3), anti-inflammatory (4), anti-cancer $(5,6)$, anti-parasitic (7), analgesic (8), antimicrobial (9), neuroprotective (10), antifungal (11), antiulcer (12), and antidiarrheal (13). The flowers of pomegranate have been ethnomedically used for their anti-cholinesterase, anti-hyperglycemic (14), anti-diabetic, anti-obesity (15), antibacterial, and antioxidant (16) effects. The constituents including gallic acid (17), ellagic acid, ethyl brevifolin-carboxylate, maslinic acid, ursolic acid, oleanolic acid, asiatic acid, sterol, daucosterol, punicaflavone, pelargonidin 3,5- 
diglucoside and pelargonidin 3-glucoside (18) are responsible for the pharmacological effects of pomegranate flower extract.

The content of phytocompounds that contributes to the antioxidant effect of the pomegranate flowers located in Adıyaman is unknown and during pomegranate juice production, antioxidant-rich flowers of pomegranates are discarded. Moreover pomegranate flowers constitutes an inexpensive source for the extraction of phytochemicals that might be utilized in the pharmaceutical, cosmetic and food industries. Thus, the objective of this research is to evaluate the nutritional quality of pomegranate flowers, which constitute the pomegranate fruit juice industry wastes. Another aim is to evaluate whether total phenolic and flavonoid contents of pomegranate flowers are correlated with antioxidant activity.

\section{MATERIAL AND METHODS}

\section{Chemicals}

Ferric chloride and 2,2-diphenyl-1-picrylhydrazyl $(\mathrm{DPPH}), \mathrm{AlCl}_{3}, \mathrm{NaNO}_{2}$, ethanol, and standard compounds, quercetin and alpha-tocopherol were purchased from Sigma Chemical Co. (SigmaAldrich $\mathrm{GmbH}$, Steinheim, Germany). Butylated hydroxytoluene (BHT) and butylated hydroxyanisole (BHA) were obtained from Acros. Folin-Ciocalteu reagent, trichloroacetic acid, and methanol were purchased from Merck. All the other chemicals used were of analytical grade.

\section{Plant material}

Dried pomegranate flowers were bought from a local shop in Adıyaman, Turkey. The flowers were ground and then the powder was kept at $4{ }^{\circ} \mathrm{C}$ until the extraction process.

\section{Preparation of Extract}

The powdered flowers $(10 \mathrm{~g})$ were extracted with n-hexane $(\mathrm{H})$, methanol (M), $1 \%$ acidified methanol (99\% methanol, AME 1 and $70 \%$ methanol, AME 2) in a Soxhlet apparatus for $4 \mathrm{~h}$. Extracts were concentrated using a rotary evaporator $\left(40^{\circ} \mathrm{C}\right)$ under vacuum and kept at 4 ${ }^{\circ} \mathrm{C}$ until analysis.

\section{Determination of total phenolic content}

The total contents of phenolic compounds were determined by the Folin-Ciocalteu method (19). The extracts were dissolved in methanol. $50 \mu \mathrm{L}$ of samples were mixed with $450 \mu \mathrm{L}$ deionized water, $250 \mu \mathrm{L}$ of $1.0 \mathrm{~N}$ Folin reagent and $1250 \mu \mathrm{L}$ of $7.5 \% \mathrm{Na}_{2} \mathrm{CO}_{3}$. The mixture was mixed in a vortex before allowed to rest for 120 minutes at room temperature and the absorbance was measured at $765 \mathrm{~nm}$. The calibration curve was plotted by different concentration of gallic acid equivalents (in $\mathrm{mg} / \mathrm{g}$ ).

\section{Determination of total flavonoid content}

The overall flavonoid content of the Punica granatum L. flower extract was estimated using the aluminum chloride colorimetric method (20). $500 \mu \mathrm{L}$ extract solution ( $1 \mathrm{mg} / \mathrm{mL}$ ) was blended with $4500 \mu \mathrm{L}$ of distilled water and $300 \mu \mathrm{L} 5.0 \%$ $\mathrm{NaNO}_{2}$. Having waited for $5 \mathrm{~min}, 300 \mu \mathrm{L}$ of $\mathrm{AlCl}_{3}$ solution was added to the blend and allowed to stand for $6 \mathrm{~min}$. Then, $2000 \mu \mathrm{L}$ of $1.0 \mathrm{M} \mathrm{NaOH}$ was added and volume increased to $10 \mathrm{~mL}$ with distilled water. The absorbance of the mixture after it turned to pink was measured at $510 \mathrm{~nm}$ using UV/Vis spectrophotometer (Shimadzu UV160). A calibration curve of standard reference was established using quercetin (range of concentration from 4 to $20 \mu \mathrm{g} / \mathrm{mL}$ ) as standard reference plotted. Total flavonoid content was expressed as $\mathrm{mg}$ of quercetin equivalents $\mathrm{g}$ extract.

\section{Determination of antioxidant activity by DPPH radical scavenging assay}

The antioxidant activity of the Punica granatum L. flower extract was determined by the DPPH (2,2-diphenyl-1-picrylhydrazyl) free radical scavenging assay (21). $1 \mathrm{~mL}$ of $0.10 \mathrm{mM} \mathrm{DPPH}$ solution was mixed with $3 \mathrm{~mL}$ of extract solution at different concentration. (12.5-125 $\mu \mathrm{g} / \mathrm{mL})$. Vigorously shaken mixture was incubated in dark at room temperature $30 \mathrm{~min}$. The absorbance was measured at $517 \mathrm{~nm}$ by a UV/Vis spectrophotometer. Butylated hydroxytoluene $(\mathrm{BHT})$, butylated hydroxyanisole (BHA) and alpha-tocopherol were utilized as standards. Using the equation below, radical scavenging percentage was calculated :

$$
\text { Radical scavenging activity }(\%)=\left[\frac{\left(A_{\text {Control }}-A_{\text {Sample }}\right)}{A_{\text {Control }}}\right] \times 100
$$

$A_{\text {control }}$ is the absorbance at the addition of ethanol instead of the extract/standard; $A_{\text {sample }}$ is the absorbance at the addition of extract/standard.
Reducing power assay 
The reducing power of different Punica granatum L. flower extracts was evaluated by the method of Oyaizu (22). $1 \mathrm{~mL}$ of the extract at different concentrations was mixed with $2.50 \mathrm{~mL}$ of phosphate buffer $(0.20 \mathrm{~mol} / \mathrm{L}, \mathrm{pH} 6.60)$ and 2.50 $\mathrm{mL} 1.0 \%$ potassium ferricyanide and vortexed. The mixture was incubated at $50{ }^{\circ} \mathrm{C}$ for 20 minutes in a water bath. $2.50 \mathrm{~mL}$ of $10 \%$ trichloroacetic acid was then added to the mixture, and centrifuged at $6000 \mathrm{rpm}$ for 10 minutes. $1.25 \mathrm{~mL}$ of supernatant was mixed with $1.25 \mathrm{~mL}$ of distilled water and $0.50 \mathrm{~mL}$ of $0.10 \%$ ferric chloride and mixed well. The absorbance of final solution was measured at $700 \mathrm{~nm}$ using a UV/Vis spectrophotometer. Higher absorbance of the reaction mixture meant higher reducing power.

\section{Metal chelating activity}

The chelation of ferrous ions of the studied extracts was observed according to the method as described by Dinis et al. (23). $50 \mu \mathrm{L}$ of $2.0 \mathrm{mM}$ $\mathrm{FeCl}_{2}$ was mixed with $3750 \mu \mathrm{L}$ of the extracts having different concentrations (12.5-125 $\mu \mathrm{g} / \mathrm{mL}$ ) and vortexed. After $10 \mathrm{~min}$ of incubation, the reaction was started by adding $200 \mu \mathrm{L}$ of $5.0 \mathrm{mM}$ ferrozine and the solution was incubated at room temperature for $20 \mathrm{~min}$ and then the absorbance of the solution was measured at $562 \mathrm{~nm}$ using a spectrophotometer. EDTA was utilized as a positive control. The percentage inhibiton of $\mathrm{Fe}^{2+}$ - ferrozine complex was calculated by the following equation:

$$
\operatorname{Inhibition}(\%)=\frac{\left(\mathrm{Abs}_{\text {control }}-\mathrm{Abs}_{\text {sample }}\right)}{\mathrm{Abs}_{\text {control }}} * 100
$$

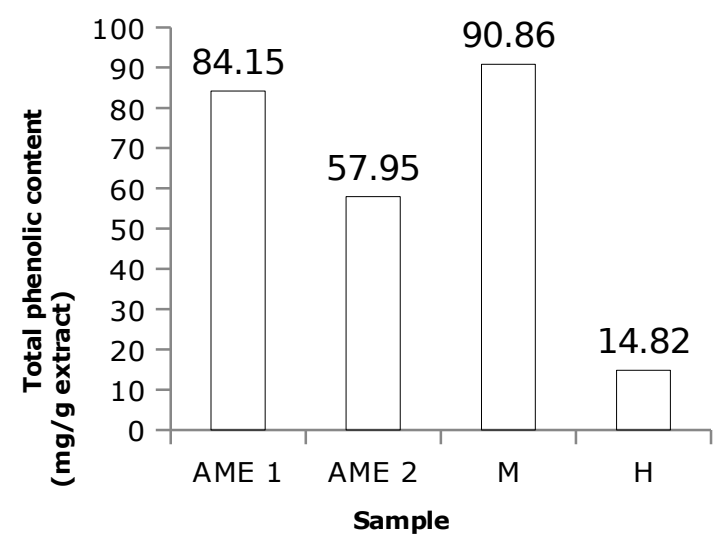

$\mathrm{A}_{\text {control; }}$ the absorbance at the addition of ethanol instead of the extract/standard, $A_{\text {sample; the }}$ absorbance at the addition of extract/standard.

\section{RESULTS AND DISCUSSION}

The yields of $n$-hexane, methanol, 1\% acidified methanol (99\% methanol and $70 \%$ methanol) extracts of the flower of $P$. granatum L. were $0.03 \%$, $15.19 \%, \quad 46.04 \%$ and $31.83 \%$, respectively.

\section{Total phenolic content}

Total phenolic contents of the extracts of pomegranate flower determined by FolinCiocalteu method are presented as gallic acid equivalents (mg gallic acid/ $\mathrm{g}$ extract) in Figure 1. The amount of total phenolic contents in the determined extracts ranged from $14.82 \pm 0.01$ to $90.86 \pm 0.01 \mathrm{mg}$ GAE / g extract. The results showed that the highest total phenolic content was obtained in the methanolic extract, while the lowest was observed in the n-hexane extract. Eddebbagh et al.(24) found that the phenolic content of $80 \%$ methanolic extract of dried pomegranate flower is $90.73 \mathrm{mg}$ GAE/ g of dry weight flowers. Abdolahi et al. (16) have found $28 \mathrm{mg}$ GAE/ g dry weight in $70 \%$ ethanolic extract and Rashid and Shafi (25) have found 190.50 and $103.81 \mathrm{mg} \mathrm{GAE} / \mathrm{g}$ in methanolic and aqueous extracts in dried pomegranate flower. These differences in phenolic contents might be due to location, soil and climate.

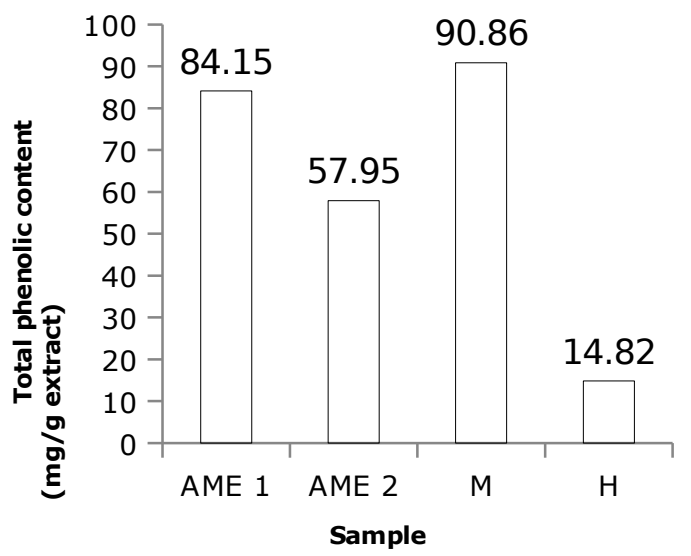

Figure 1. Total phenolic content as equivalent mg Figure 2. Total flavonoid content as equivalent mg of gallic acid per $g$ of AME 1, AME 2, $M$ and $H$ of quercetin per $g$ of $A M E 1, A M E 2, M$ and $H$ extracts of pomegranate flower. extracts of pomegranate flower.

\section{Total flavonoid content}

The total flavonoid contents in the determined extracts of pomegranate flowers are expressed in 
terms of quercetin equivalent (mg quercetin/ $\mathrm{g}$ extract) in Figure 2. The flavonoid content was $350.74 \pm 0.01, \quad 172.79 \pm 0.02,500.00 \pm 0.01$ and 7.35 $\pm 0.01 \mathrm{mg}$ QUE $/ \mathrm{g}$ in AME 1, AME 2, M and $\mathrm{H}$ extracts, respectively. The results showed that the greatest total flavonoid content was obtained in the methanolic extract. Eddebbagh et al. (24) have found $221.70 \mathrm{mg}$ QUE/ g dry weight in $80 \%$ methanolic extract and Abdolahi et al. (16) have reported $64.38 \pm 0.81 \mathrm{mg}$ catechin equivalents per gram of dry weight in dried pomegranate flower. These differences might be related to solvent used and location.

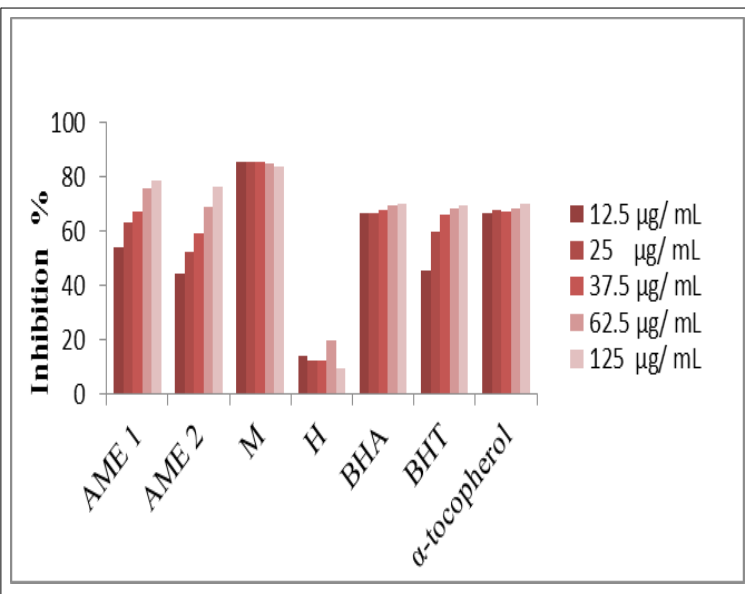

Figure 3. DPPH • radical scavenging activity(\%) of AME 1, AME 2, $M$ and $\mathrm{H}$ extracts of pomegranate flower.

\section{DPPH radical scavenging activity}

DPPH radical scavenging activity of the pomegranate flower extracts is summarized in Figure 3 and compared with the standard antioxidants such as BHA, BHT and a-tocopherol. The potential of different pomegranate flower extracts to scavenge free radical varied 54.12$78.54 \%$ in AME $1,44.22-76.56 \%$ in AME 2, $83.82-85.80 \%$ in $M$ and $9.57-19.80 \%$ in $H$. Among them, the methanolic extract exhibited the higher values of DPPH radical scavenging activity. Pomegranate flower extracts clearly showed that as the concentration got higher the antioxidant activity against DPPH radical in all extracts increased. Abdolahi et al. (16) have reported $91.04 \%$ inhibition at concentration of $100 \mu \mathrm{g} / \mathrm{mL}$ pomegranate flower extract. On the other hand, Rashid and Shafi (25) have found $76.89 \%$ and $69.23 \%$ in methanolic and aqueous extract of flowers of pomegranate, respectively.
These differences can also be explained with soil and climate differences.

\section{Reducing power activity}

Reducing power activities of extracts are shown in Figure 4 with standard antioxidant compounds (BHA, BHT and a-tocopherol). The reducing power of the all extracts dose with the increase in concentration (Table 1 ). In addition, methanolic extract showed 2.93 times stronger antioxidant activity than that of a-tocopherol at an initial concentration of $5.88 \mu \mathrm{g} / \mathrm{mL}$. In the literature, the reducing properties are usually related to the presence of reductones (reducing agents) which have been found to exert antioxidant ability to break the free radical chain by donating a hydrogen atom (26). So, the data gathered from the present study suggest that pomegranate flower might contain polyphenol which acts as reducing agents. 
Tekin Z, Küçükbay FZ. JOTCSA. 2020; 7(1): 37-42.

Table 1. Reducing power activity of AME 1, AME 2, M and $\mathrm{H}$ extracts of pomegranate flower.

\begin{tabular}{|c|c|c|c|}
\hline \multirow{2}{*}{ Extracts/Standards } & \multicolumn{3}{|c|}{ Reducing Power ( $\mathbf{g g} / \mathbf{m L} \mathbf{7 0 0} \mathbf{~ n m})$} \\
\cline { 2 - 4 } & $\mathbf{5 . 8 8}$ & $\mathbf{1 4 . 7 0}$ & $\mathbf{2 9 . 4 1}$ \\
\hline AME 1 & 0.260 & 0.613 & 1.004 \\
\hline AME 2 & 0.179 & 0.342 & 0.653 \\
\hline M & 0.419 & 0.878 & 1.683 \\
\hline H & 0.085 & 0.106 & 0.174 \\
\hline BHA & 0.507 & 1.028 & 1.900 \\
\hline BHT & 0.244 & 0.525 & 0.953 \\
\hline a-tocopherol & 0.143 & 0.410 & 0.841 \\
\hline
\end{tabular}

\section{Metal chelating activity}

Metal chelating activity of the pomegranate flower extracts and EDTA are presented in Table 2. n-Hexane extract possessed moderate metal chelating activity whereas all the other extracts exhibited none. The highest metal chelating activity of $9.299 \%$ was determined in n-hexane extract.

Table 2. Metal chelating activity of AME 1, AME 2, M and $\mathrm{H}$ extracts of pomegranate flower.*ND; nondetected.

\begin{tabular}{|c|c|c|c|c|c|}
\hline \multirow{2}{*}{ Extracts/ Standard } & \multicolumn{5}{|c|}{ Inhibition, $\%$} \\
\cline { 2 - 6 } & $\begin{array}{c}\mathbf{1 2 . 5} \\
\mathbf{\mu g / \mathbf { m L }}\end{array}$ & $\mathbf{2 5} \mathbf{\mu g / \mathbf { m L }}$ & $\begin{array}{c}\mathbf{3 7 . 5} \\
\mathbf{\mu g} / \mathbf{m L}\end{array}$ & $\begin{array}{c}\mathbf{6 2 . 5} \\
\mathbf{\mu g} / \mathbf{m L}\end{array}$ & $\begin{array}{c}\mathbf{1 2 5} \\
\mathbf{\mu g} / \mathbf{m L}\end{array}$ \\
\hline AME 1 & *ND & ND & ND & ND & ND \\
\hline AME 2 & ND & ND & ND & ND & ND \\
\hline M & ND & ND & ND & ND & ND \\
\hline H & ND & 0.104 & 1.149 & 1.985 & 9.299 \\
\hline EDTA & 8.045 & 40.020 & 56.426 & 78.892 & 84.430 \\
\hline
\end{tabular}

\section{CONCLUSION}

Our results show that the flowers of $P$. granatum may have health benefits when consumed. Our belief is that they display potential as a functional food or value-added ingredient for years to come. Also $P$. granatum flower might be considered a source of important antioxidant with bioactive properties to be explored for pharmaceutical applications. Further studies can be undertaken to investigate the effect of toxicity in these extracts.

\section{REFERENCES}

1. Kalaycıoğlu Z., Erim FB., Total phenolic contents, antioxidant activities, and bioactive ingredients of juices pomegranate cultivars worldwide, Food Chemistry, 2017; 221; 496-507.

2. TÜİK, Turkish Statistical Institute,2019, http://tuik.gov.tr
3. Adhami VM., Mukhtar H., Polyphenols from green tea and pomegranate for prevention prostate cancer, Free Radic. Res. 2006; 40; 1095-104.

4. Colombo E., Sangiovanni E., Dell'Agli M., A review on the anti-inflammatory activity of pomegranate in the gastrointestinal tract., Evidence-Based Complementary and Alternative Medicine, 2013; 1-12.

5. Lansky EP., Newman RA., Punica granatum (pomegranate) and its potential for prevention and treatment of inflammation and cancer, Journal of Ethnopharmacology, 2007; 109; 177-206.

6. Sharma P., McCless .F., Afaq F., Pomegranate for prevention and treatment of cancer: an update, Molecules, 2017; 22(1); 177.

7. Williams AR., Soelberg J., Jäger AK., Anthelmentic properties of traditional African and Carribbean medicinal plants: identification of extracts with potential activity against Ascaris suum in vitro, Parasite, 2016; 23(24);1-6.

8. Nadia Z., Aicha M., Sihem H., Abdelmalik B., In vivo analgesic activities and safety assesment of Vitis 
vinifera $\mathrm{L}$ and Punica granatum $\mathrm{L}$ fruits extracts, Tropical Journal of Pharmaceutical Research, 2017; $16(3) ; 553-61$.

9. Bassiri-Jahromi S., Doostkam A., Comparative evaluation of bioactive compounds of various cultivars of pomegranate (Punica granatum) in different world regions, AIMS Agriculture and Food, 2019; 4(1); 41-55.

10. DaSilva NA., Nahar PP., Ma H., Eid A., Wei Z., Meschwitz S., Zawia NH., Slitt AL., Seeram NP., Pomegranate ellagitannin-gut microbial-derived metabolites, urolithins, inhibit neuroinflammation in vitro, Nutritional Neuroscience, 2019; 22(3); 185-95.

11. Sharayei P., Azarpazhooh E., Zomorodi S., Ramaswamy HS., Ultrasound assisted extraction of bioactive compounds from pomegranate (Punica granatum L.) peel, LWT, 2019; 101; 342-50.

12. Moghaddam G., Sharifzadeh M., Hassanzadeh G., Khanavi M., Dolatshahi F., Sadeghi N., Oveisi MR., Hajimahmoodi M., Anti-ulcerative potential of Punica granatum L. (Lythraceace) hydroalcohol fruit peel extract,Tropical Journal of Pharmaceutical Research, $2014 ; 13(7) ; 1093-7$.

13. Zhao S-S., Ma D-X., Zhu Y., Zhao J-H., Zhang Y., Chen J-Q., Sheng Z-L., Antidiarrheal effect of bioactivity-guided fractions and bioactive components of pomegranate (Punica granatum L.) peels, Neurogastroenterology \&amp; Motility, 2018; 30(7); 110.

14. Bekir J., Cazaux S., Mars M., Bouajila J., In vitro anti-cholinesterase and anti-hyperglycemic activities of flowers extracts from seven pomegranate varieties, Industrial Crops and Products, 2016; 81; 176-9.

15. Wu S., Tian L., A new flavone glucoside together with known ellagitannins and flavones with anti-diabetic and anti-obesity activities from the flowers of pomegranate (Punica granatum), Natural Product Research, 2019; 33(2); 252-7.

16. Abdolahi N., Soltani A., Mirzaali A., Soltani S., Balakheyli H., Aghaei M., Antibacterial and antioxidant activities and phytochemical properties of Punica granatum flowers in Iran, Iranian Journal of Science and Technology, Transactions A: Science, 2018; 42; 1105-10.

17. Huang THW., Peng G., Kota BP., Li GQ., Yamahara J., Roufogalis BD., Li Y., Anti-diabetic action of Punica granatum flower extract: Activation of PPAR- $y$ and identification of an active component, Toxicology and Applied Pharmacology, 2005; 207(2); 160-9.

18. Bekir J., Mars M., Vicendo P., Fterrich A., Bouajila J., Chemical composition and antioxidant, antiinflammatory and antiproliferation activities of pomegranate (Punica granatum) flowers, Journal of Medicinal Food, 2013; 16(6); 544-50.

19. Singleton VL., Rossi JA., Colorimetry of total phenolics with phosphomolybdic-phosphotungstic acid reagents, American Journal of Enology and Viticulture, $1965 ; 16 ; 144-58$.

20. Zhishen J., Mengcheng T., Jianming W., The determination of flavonoid contents in mulberry and their scavenging effects on superoxide radicals, Food Chemistry, 1999; 64(4); 555-9.

21. Blois MS., Antioxidant determinations by the use of a stable free radical, Nature, $1958 ; 181 ; 1199-200$.

22. Oyaizu M., Studies on product of browning reaction prepared from glucose amine, Japanese Journal of Nutrition, 1986 ; 44; 307-15.

23. Dinis TCP., Madeira VMC., Almeida LM., Action of phenolic derivatives (acetaminophen, salicylate, and 5aminosalicylate) as inhibitors of membrane lipid peroxidation and as peroxyl radical scavengers, Archives of Biochemistry and Biophysics, 1994; 315(1); 161-169.

24. Eddebbagh M., Messaoudi M., Abourriche A., Berrada M., Attaleb M, Benbacer L., Bennamara A., Correlation of the cytotoxic and antioxidant activities of Moroccan pomegranate (Punica Granatum) with phenolic and flavonoid contents, Journal of Pharmacy and Pharmacology, 2016; 4; 511-9.

25. Rashid M., Shafi S., Evaluation of in vitro antioxidant and anti-diabetic potential of Kashmiri pomegranate (Punica granatum Linn.) flower extract, International Research Journal of Pharmacy, 2018; 9(9); 117-24.

26. Elfellah W., Hannachi H., Tlili N., Yahia Y., Nasri N., Ferchichi A., Total phenolic contents and antioxidant activities of pomegranate peel, seed, leaf and flower, Journal of Medicinal Plants Research, 2012; 6; 472430. 